\title{
A Self-evaluation of Classroom Language Used When Teaching Grammar
}

\author{
Fang Huan \\ School of Foreign Language, Yan'an University, Shaanxi, 716000, China \\ E-mail: tinahuanfang@ hotmail.com \\ Li Wang (Corresponding Author) \\ School of Foreign Language, Yan'an University, Shaanxi, 716000, China \\ E-mail: wangli8179225@126.com
}

Received: December 23, 2010 Accepted: January 14, 2011 Published: November 1, 2011

doi:10.5539/ies.v4n4p170

URL: http://dx.doi.org/10.5539/ies.v4n4p170

\begin{abstract}
In the attempt to evaluate the quality of teacher talk, recent communicative approaches have suggested that the modification of teacher classroom speech and the functional distribution of teacher talk in terms of pedagogical goals should be considered (Seedhouse: 1996). This study investigates the relationship between language use and pedagogic purpose from an analysis of a lesson transcript of a grammar lesson, and evaluates the quality of the teacher talk based on the Self-Evaluation of Teacher Talk (SETT) Grid. The purpose is to examine whether the teacher talk is appropriate in the classroom context or mode and to bring about a more conscious and effective use of teacher talk in her teaching profession in the future.
\end{abstract}

Keywords: Teacher talk, Self-Evaluation of Teacher Talk (SETT)

\section{Introduction}

Since the 1960s, there has been an interesting topic in the research into communication between teachers of English as a Second Language and learners. There have been extensive investigations into the types and relative quantities of participation by the teacher and the students, and the functions and forms of language performed in the interaction (Chaudron, 1988). However, the recent theoretical attention to 'comprehension input' in L2 teaching has led to a substantial amount of research on L2 teacher speech, often referred to as 'teacher talk' (ibid.).

One of the principal questions addressed by the research on L2 teacher talk is whether or not teachers adjust their speech to the L2 learner in a qualitative way. The interest in studying how effectively they are able to promote the interaction in the L2 classroom is more focused, while the dominance of teacher speech is considered to be undesirable (Cullen, 1998). One of the convincing reasons is if the teachers devote large amounts of time to explanations or management instructions, or spend much time in drills or drill-like questioning, the learners may thus have less opportunity to evaluate input or produce creative target language.

In the attempt to evaluate the quality of teacher talk, recent communicative approaches have suggested that the modification of teacher classroom speech and the functional distribution of teacher talk in terms of pedagogical goals should be considered (Seedhouse: 1996). According to Walsh (2003), there are four 'modes' of teacher talk in the L2 classroom.

Skills and systems mode - main focus is on particular language items or vocabulary

Managerial mode - main focus is on setting up an activity

Materials mode - main focus is on the use of text, tape or other materials

Classroom context mode - main focus is on eliciting feelings, attitudes, etc.

It is seen that teacher speech displays a variety of modifications depending on the nature of the task and the competence of the learners. Perhaps of greater interest to classroom researchers is the question of how teacher talk is distributed, that is, how it differs in function and to what extent it is appropriate to the pedagogic purpose, which enhances L2 learners' comprehension and their consequent ability to process the target language grammar and lexis (Chaudron, 1988). 
This study investigates the relationship between language use and pedagogic purpose from an analysis of a lesson transcript made by the author from a video recording of a grammar lesson, and evaluates the quality of the teacher talk based on the Self-Evaluation of Teacher Talk (SETT) Grid. The purpose is to examine whether the teacher talk is appropriate in the classroom context or mode and to bring about a more conscious and effective use of teacher talk in her teaching profession in the future.

\section{Procedure}

The procedure of the study started with the teaching of a grammar lesson, aiming to introduce the idea of 'the present'; to teach the use of the Present Continuous tense; and to give the learners opportunity to manipulate the new grammar point. By the end of the class, the learners should be able to talk about temporary present actions and produce the correct form of the Present Continuous tense. The function of the grammar point was to describe the action at the present. Five trainee-teachers were involved and they role-played L2 learners who had just learned two basic tenses, the Simple Present tense and the Simple Post tense. It was also assumed that they had learned quite a few state-verbs like stand, sit or sing, though they did not necessarily know what the terminology was.

From previous learning and teaching experiences as an L2 learner and teacher, the form of the tense was easy to construct. The only formal problem was likely to be the inflection of the -ing verb forms. Besides, it is important (though not very easy) to practise the tense realistically as far as possible. The reason is that people generally ask or say what is happening is a situation where it may not be possible to see or understand what is going on. Moreover, state-verbs like stand, sit may present problems for some non-native learners. As a matter of fact, the equivalent in some languages of, for instance, he's standing, might not be constructed with an active verb-form at all, but a passive, a past participle or even an adjective.

Concerning the teaching objectives and participation problems, a picture of a person on the pone, telling another person what was happening in a party was used to produce a more realistic situation, where the action was being carried out, thus helping to introduce the Present Continuous tense. In the lesson, the teacher produced the correct tense form at first, and then L2 learners were invited to manipulate the new form of the tense and their responses were elicited and evaluated. Meanwhile, the errors were tolerated and corrected when they occurred. For the explanation of the inflective verb form in the Present Continuous tense, the amount of input and the avoidance of overload had been considered beforehand.

A ten-minute extract of the lesson was recorded and reviewed right after the lesson was taught. With regard to the objectives set for the lesson and the four modes Walsh stated, I identified that for the segment of my teacher talk the Materials mode and the Skills and Systems mode were in operation. Afterwards, the extract of the recorded teaching was transcribed and the SETT instrument (Walsh,2003) was used to keep a tally (See Appendix I), helping to decide whether the language used during the segment of the lesson matched the stated pedagogic goals in each mode. The result of the investigation should be able to evaluate the quality of my teacher talk in the grammar lesson.

\section{Analysis}

Having been given a close examination of the transcript, the following features were found in the teaching talk. The most commonly occurring pattern of interaction was IRF structure. As Sinclair and Coulthard (1975) identified in their now well known analysis of classroom discourse, 'I' represents an initiating move, such as a question posed by the teacher; ' $R$ ' is the response from the class - usually from an individual student and ' $F$ ' is the follow-up or feedback comment by the teacher. The structure of the IRF was repeated quite a few times in the transcript. Taking one of them as the example:

$<30>$ T: Can you think of a verb to describe your action, Sanda? (I)

$<31>$ S5: Drink. (R)

$<32>$ T: That's right. (F)

Although the IRF structure involving the majority of the initial moves of the teacher has been the target of some criticism in the communicative language teaching movement (Thornbury, 1996), I still instinctively adopt it in my teaching. This is because I find it useful and practical as a pedagogic device for transmitting and constructing the information I plan to present. As the stage of presentation in the lesson, the pedagogic goals were to encourage the learners to talk about the picture, but my intention was to focus on the verbs which would form the main part of the lesson. The IRF pattern appeared every time when I elicited responses from the students by asking what the actions of the persons were in the picture and they responded, followed by my feedback.

Although feature of my teacher talk involved in the IRF structure was the Display questions (asking questions to which the teacher knows the answer) when I was eliciting the answers from the students. For example: 
<44>T: Who's left?

$<45>$ Ss: Michael.

$<46>\mathrm{T}$ : What about him?

$<47>$ Ss: Talk on the phone.

Meanwhile, the Direct repair (correction an error quickly and directly) was combined with IRF structure. For example:

$<21>$ S4: I drank champagne.

$<22>\mathrm{T}$ : Really? Was it good?

$<23>$ S4: Yes, it is very good.

$<24>$ T: Chris, it WAS very good. All right?

Except for one occasion, I was trying to negotiate the answer I wanted with the student instead of correcting them immediately.

$<40>$ S5: Talk.

$<41>$ T: Well, Karla. Can you think of another word to describe her action? It also means 'talk'.

$<42>$ T: See Sharon talks with her friends and they laugh and ...Um... (1 sec)

$<43>$ S5: Chat.

$<44>$ T: That's the word. Excellent.

The reason for doing this was because the word 'talk' was the one I particularly wanted and I did not want the student feel discouraged either. Therefore, I was trying to elicit the word chat which would be needed in the following lesson by providing more information that might lead the students to the targeted one.

Besides, the use of Scaffolding, such as extending a learner's contribution was also evident when I evaluated the students' answers and gave them feedback. By completing the student's answer, I was indicating that complete sentences were expected from their contributions. For example:

$<16>\mathrm{T}$ : And you, Kelly?

$<17>$ S3: I sang.

$<18>\mathrm{T}$ : You sang songs. Did you?

$<19>$ S3: Yes.

All the features of my teacher talk mentioned above, to a great extent, match the pedagogic goals in the Materials mode, which was intended to be in operation at the first stage of the lesson. It seemed that the interaction around the talk about the picture was well-controlled and the pre-determined responses were expected. However there were still Referential questions (genuine questions to which the teacher does not know the answer) asked which was stated by Nunan (1988:139) as one of characteristics of the genuine communication, shown as in the example:

$<10>$ T: Sharon, what did you do at the party?

$<11>$ S1: I ate a lot.

At the produce and practice stage of the lesson, the Skills and Systems mode should be operated, aiming to teach the Present Continuous tense and to invite the students to manipulate the new grammar point. The distinguishing features of the teach talk in this mode were the Extended teacher turns and the Teacher echo. The Extended teacher turns happened when I started the explanation $\langle 75\rangle$ of what the Present Continuous tense was used for. The extended time seemed long in terms of the interaction with the students, but I think it was necessary to spend sufficient time on clarifying the new knowledge before the learners took turns to practice it. During the explanation I kept repeating the word now and stressed it in order to emphasize that the time in this tense focused on 'the present'. Considering the amount of input at one time, I encouraged the students to produce the present continuous sentence right after the example was given at the end of my explanation. The rules of the form of the verb inflection were briefly explained only when the students came across the irregular verbs. The students were also told that more opportunity for practice would be given later so that they could produce the correct form. In this way, the Extended teacher turns would not be overloaded for the learners.

The teacher echo (teacher repeats a learner's contribution) was found in my teacher talk several times. The purpose of it was to reinforce the new knowledge. In addition to that, the implied advantage of my teacher echo 
worked as a signal of conforming the students' answers which built up their confidence in manipulating the Present Continuous tense. For example:

$<78>$ Ss: Philip is shouting.

<79> T: Very good. Philip is shouting.

In order not to repeat the explanation of the rule which formed the irregular verb inflection and with the aim of reviewing it, the teacher asked the students to clarify something that the teacher had said. While this clarification request was not really in the SETT, I think it was properly practiced in my teacher talk and it suited the pedagogic goal. I did not ask the students to explain everything because it might cause them tension and shit the pedagogic goal, namely producing and practicing the correct -ing form of irregular verbs. Further, they might have wrongly assumed that the goal was to memorize the grammatical rule and present it orally. Instead, the students were expected to recall some key words that highlighted the rule while the teacher still played the main role in the interaction. For example:

$<90-1>$ T: Please remember, a one-syllable verb ends in a ... (2sec)

$<92>$ Ss: Vowel.

$<93>$ T: And a ... (2sec)

$<94>$ Ss: Consonant.

$<95>$ T: The last letter should be ... (2sec)

$<96>$ Ss: Doubled.

$<97>$ T: Brilliant.

\section{Conclusion}

As shown in this extract, the Extended wait-time (allowing sufficient time for the students to response or formulate a response) was spontaneous. I think it was effectively used in this situation since the contribution from the students was important and it was necessary to wait for the answer so that I could make sure that they had grasped the rule.

By analyzing the teacher talk at the second stage, it appears that the extended teacher turns and teacher echo were conducted with the aim of producing correct forms and giving corrective feedback; the clarification requests and Extended wait-time in the teacher talk were used when it was necessary to avoid the teacher-centred type of lesson, leaving enough opportunities and time for the students to participate in the interaction.

Studies of classroom talk tend to suggest that the classroom is a world of its own, with its own rules and conversations, and the language that the teachers use is on importance in the analysis of interaction in the second language classroom (Lier, 1984). This study has provided me an opportunity to reflect on my own type of teacher talk and brought me a close look at the quality of the language I used in teaching. I took time to produce a good transcript, but it was well invested. The findings can guide me to more awareness of qualitative teacher talk in future teaching.

\section{References}

Chaudron, (1988). Second Language Classroom: Research on Teaching and Learning, Cambridge: Cambridge University Press.

Cullen. (1998). Teacher Talk and the Classroom Context, ELT Journal, Vol.52, No.3, 179-187

Cullen. ( 2002). Supportive Teacher Talk: the importance of the F-move, ELT Journal, Vol.56, No.2, 117-127

Lier. (1984). Analysing Interaction in Second Language Classrooms, ELT Journal, Vol.38, No.3, 160-169

Nunan, (1987). Communicative Language Teaching: making it work, ELT Journal, Vol.41, No.2, 136-45

Seedhouse, (1996). Classroom Interaction: possibilities and impossibilities, ELT Journal, Vol.50, No.1, 16-24

Sinclair, J., \& M. Coulthard Towards an Analysis of discourse: the English Used by Teachers and Pupils, Oxford: Oxford University Press.

Thornbury. (1996). Teachers Research Teacher Talk, ELT Journal, Vol.50, No.4, 279-289

Walsh. (2003). Construction or Obstruction: Teacher Talk and Learners Involvement, EFL Classroom, Language Teaching, Vol.6, No.1, 3-23 
Appendix I

\begin{tabular}{|l|l|l|}
\hline \multicolumn{1}{|c|}{$\begin{array}{c}\text { FEATURE OF TEACHER } \\
\text { TALK }\end{array}$} & \multicolumn{1}{c|}{ TALLY } & \\
\hline A. Scaffolding & & \\
\hline B. Direct repair & & \\
\hline C. Content feedback & & \\
\hline D. Extended wait-time & & \\
\hline E. Referential questions & & \\
\hline F. Seeking clarification & & \\
\hline H. Extended learner turn & & \\
\hline I. Teacher exho & & \\
\hline J. Teacher interruptions & & \\
\hline K. Extended teacher turn & & \\
\hline L. Turn completion & & \\
\hline M. Display questions & & \\
\hline N. Form-focused feedback & & \\
\hline
\end{tabular}

